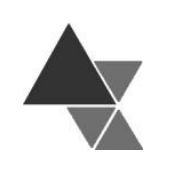

\title{
Qualidade da alimentação escolar a partir da aquisição de produtos da agricultura familiar
}

\author{
Aline Luiza Führ ${ }^{1}$ e Rozane Marcia Triches ${ }^{2}$
}

Este estudo buscou verificar qual a repercussão da aquisição de alimentos da agricultura familiar para a qualidade nutricional de refeições oferecidas pela alimentação escolar em dois municípios do estado do Paraná (município A e B). Foram utilizadas chamadas públicas, editais de licitação, prestações de contas e cardápios escolares referentes ao ano de 2013. Os cardápios foram avaliados quantitativamente, com auxílio do programa Avanutri®. Esta análise foi complementada com a análise dos mecanismos de compras. Os resultados foram organizados por meio de estatística descritiva com o Microsoft Excelß e Statistical Package for the Social Science. O município que realizou maior aquisição de produtos provenientes da agricultura familiar também efetuou maiores investimentos em frutas e vegetais; adquiriu maior variedade de alimentos e apresentou cardápios mais adequados em macronutrientes, alguns micronutrientes, fibras e energia. Em ambos os municípios não houve adequação dos valores de cálcio, magnésio e zinco. As chamadas públicas garantiram a oferta de maior percentual de alimentos recomendados em relação às licitações. Os resultados apresentados exprimem que a aquisição de alimentos da agricultura familiar permite o planejamento de um cardápio mais adequado, influenciando positivamente na qualidade do consumo alimentar dos escolares.

Palavras-chave: qualidade, alimentação escolar, agricultura familiar, segurança alimentar e nutricional.

\section{Nutritional quality of school feeding as from family farms food purchase}

This study aimed to verify a repercussion of the acquisition of food from family farms for a nutritional quality of meals offered by school feeding in two municipalities of the state of Paraná (municipality A and B). There is a list of publications, bids, accounts and school menus for the year 2013. The menus were quantitatively evaluated with the help of the Avanutri ${ }^{\circledR}$ program. This analysis was complemented by an analysis of purchasing mechanisms. The results were organized through descriptive statistics with Microsoft Excel ${ }^{\circledR}$ and Statistical Package for Social Sciences. The municipality that made the largest purchase of agricultural products from family agriculture also made larger investments in fruits and vegetables; acquired a greater variety of foods and presented more adequate menus in macronutrients,

\footnotetext{
${ }^{1}$ Nutricionista residente em Saúde da Familia. Universidade Federal da Integração Latino-Americana. Edifício Comercial Lorivo. Endereço para correspondência: Av. Silvio Américo Sasdelli no 1842, Vila A, Foz do Iguaçu, PR. Tel.: (49) 98819-1173. E-mail: alineluizafuhr@gmail.com

${ }^{2}$ Docente do Curso de Nutrição da Universidade Federal da Fronteira Sul, Campus Realeza, PR. Rua Edmundo Gaievisk no 1.000, Zona Rural, Realeza, PR. Tel.: (46) 99902-0083. E-mail: rozane.triches@gmail.com
} 
some micronutrients, fibers and energy. In both municipalities there was no adequacy of calcium, magnesium and zinc values. As public lines guaranteed an offer of higher percentage of recommended food in relation to the bids. The results indicate that the acquisition of food from family farming allows the planning of a more appropriate menu, positively influencing the quality of food consumption of schoolchildren.

Keywords: quality, school feeding, family farmer, food and nutrition security.

\section{INTRODUÇÃO E OBJETIVOS}

O Programa Nacional de Alimentação Escolar (PNAE) é considerado um dos maiores programas na área de alimentação escolar no mundo. Ao completar mais de 50 anos de execução atendeu mais de 250 mil escolas no Brasil $^{[1]}$ e especificamente no período de 2005 a 2012 passou de 33,2 milhões para 43,1 milhões de alunos atendidos, com importante acréscimo financeiro para isso ${ }^{[2]}$.

Sua complexidade e importância se fortaleceram principalmente a partir da descentralização dos recursos, no ano de 1994 e das políticas de SAN. Desde então, distintas iniciativas buscaram a aquisição de alimentos de agricultores locais no sentido de garantir mercados para os agricultores familiares e disponibilizar alimentos adequados a crianças e adolescentes. Tais iniciativas e a experiência do Programa de Aquisição de Alimentos repercutiram na implantação do Artigo 14 da Lei 11.947/2009, com obrigatoriedade de aplicação de no mínimo 30\% dos recursos do Fundo Nacional de Desenvolvimento da Educação (FNDE) em gêneros da agricultura familiar, por dispensa de licitação ${ }^{[3,4]}$.

Nesse contexto, torna-se notório que o nutricionista como Responsável Técnico, ao realizar a elaboração dos cardápios, considere a produção de alimentos da agricultura familiar local e atente para suas peculiaridades ${ }^{[3,5]}$. Uma vez que para alguns autores ${ }^{[6,7]}$, a aquisição de produtos da agricultura familiar para o PNAE possibilitaria a permanência de família de pequenos agricultores no campo com qualidade de vida; manutenção dos saberes/estilos de vida locais e o consumo de alimentos culturais; inclusão social, participação política e democrática de agricultores; aproximação entre a produção e o consumo; transferência de recursos diretamente aos agricultores; preservação da biodiversidade; desenvolvimento e aquecimento da economia local; bem como, o emprego de práticas produtivas ecologicamente mais equilibradas e sustentáveis (a partir da diversificação de cultivos, menor uso de insumos industriais e a preservação do patrimônio genético).

Ademais, esta aproximação também permitiria uma relação positiva entre $O$ fornecimento de alimentos da agricultura familiar e a ampliação da oferta de vegetais e frutas servidos nas refeições escolares, o que teoricamente deveria repercutir na melhoria da qualidade dos cardápios elaborados. Ainda, existe a afirmação de que haveria uma modificação no nível do consumo de alimentos mais saudáveis e adequados no que tange à aceitação dos alunos, associada a novas perspectivas de mercado para a agricultura familiar e ao fomento às práticas de produção consideradas menos nocivas ao ambiente ${ }^{[8]}$. Por outro lado, estudo aponta que a aquisição de produtos da agricultura familiar não seria o suficiente para melhorar a qualidade nutricional dos cardápios ${ }^{[9]}$. 
Sendo assim, este trabalho justifica-se no sentido de buscar mais informações sobre esta questão, visto que há poucos estudos avaliando se a aquisição de produtos da agricultura familiar tem melhorado a qualidade nutricional da alimentação escolar. Portanto, seu objetivo é verificar a repercussão da aquisição de alimentos da agricultura familiar em relação à qualidade nutricional de refeições escolares em dois municípios do estado do Paraná. Com isso pretendeu-se identificar: a) distinções ou semelhanças na adequação nutricional dos cardápios de municípios com níveis diferenciados de aquisição de produtos da agricultura familiar; e, b) analisar as modalidades de compra de alimentos (processos licitatórios e chamadas públicas) em relação à quantidade de produtos recomendados e controlados.

\section{MATERIAL E MÉTODOS}

Trata-se de um trabalho de caráter transversal, quantitativo e descritivo, desenvolvido por meio de informações obtidas a campo e fundamentado pela comparação entre dois municípios paranaenses. Os mesmos foram selecionados partir dos seguintes critérios: a) apresentar menos de 20 mil habitantes (considerando que o estado se constitui, majoritariamente, por municípios deste tamanho); b) possuir condições socioeconômicas parecidas - Produto Interno Bruto (PIB), Coeficiente de GINI e Índice de Desenvolvimento Humano (IDH); c) dispor de percentuais históricos distintos de aquisição de produtos da agricultura familiar (2010 a 2014) e d) pertencerem a regiões diferentes (sudoeste e oeste do estado). A partir destes critérios, foram elencados os possíveis municípios participantes e, dentre eles, escolhidos dois, aleatoriamente. No entanto, só chegou-se a definição dois municípios pesquisados (Município A e Município B) após a anuência dos representantes das prefeituras em participar do estudo.
A coleta de dados envolveu a obtenção das chamadas públicas, editais de licitação, prestações de contas e cardápios escolares propostos pelo responsável técnico de ambos os municípios, referentes ao ano de 2013. Isso a partir de contato telefônico, e-mail ou visita pessoal. A qualidade dos cardápios propostos foi avaliada por meio do atendimento das recomendações nutricionais e análise das compras.

A análise nutricional ocorreu pelas seguintes etapas: 1) cálculo do per capita planejado para cada produto; 2) cálculo dos valores médios de macro e micronutrientes de uma semana dos cardápios planejados; 3) análise da adequação nutricional dos cardápios em relação às recomendações da Resolução $\mathrm{n}^{\circ}$ $26 / 2013^{[10]}$.

$\mathrm{Na}$ primeira etapa foi utilizado o

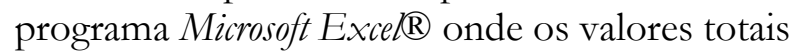
de cada alimento foram corrigidos pelo fator de correção (FC) (FC= Peso Bruto/Peso Líquido) recomendado ${ }^{[11,12]}$. O valor encontrado foi dividido pela frequência das preparações no ano e posteriormente pelo total de alunos referidos pelo Censo Escolar de 2013. Assim, foi encontrado o quantitativo em gramas teoricamente oferecidos para cada aluno de cada de alimento.

$\mathrm{Na}$ segunda etapa, os cardápios foram avaliados de acordo com o método já previamente proposto por Domene et al. ${ }^{[13]}$. Foram utilizados cinco dias (uma semana) do mês de junho de 2013, no qual as preparações propostas foram avaliadas nutricionalmente pelo programa Avanutri ${ }^{[14]}$, de acordo com o per capita calculado. A partir disso, foram obtidos os valores de nutrientes, fibra e energia média/dia, os quais foram avaliados por meio de média semanal, pelo Microsoft Excel® e Statistical Package for the Social Science (SPSS) versão 19 ${ }^{[15]}$. Tais valores foram então comparados às recomendações estabelecidas pela Resolução 
26/2013 (calorias, proteínas, lipídeos, carboidratos, gorduras saturadas, vitaminas A e C, cálcio, magnésio, ferro, zinco e sódio) ${ }^{[10]}$. Para tanto, foi calculcada a média entre as recomendações estabelecidas para escolares de 6-10 anos e 11-15 anos ${ }^{[10]}$, pela qual foi possível estabelecer o percentual de adequação dos nutrientes encontrados nos cardápios avaliados, e posteriormente análise estatística da distribuição dos dados com o uso do Teste $T$ Student Independent ${ }^{[15]}$ com um nível de significância de $p<0,05$. Foram considerados adequados, percentuais com no mínimo $80 \%$ de adequação e no máximo $120 \%$.

A análise das compras foi realizada por meio do Método de Avaliação da Aquisição de Gêneros Alimentícios (AGA) ${ }^{[16]}$. Inicialmente as compras foram avaliadas com o programa Excel ${ }^{\circledR}$, sendo buscados aspectos como: quantidade total de cada gênero alimentício adquirido em quilogramas, preço por unidade, preço total por alimento adquirido, observandose a quantidade total de cada grupo de alimentos e o investimento financeiro destinado a cada categoria. Após foram verificados os percentuais de investimento financeiros utilizados para aquisição de alimentos recomendados e controlados, de acordo com classificação definida pelos autores do método ${ }^{[16]}$.

\section{RESULTADOS E DISCUSSÃO}

De acordo com a Tabela 1, o município B destacou-se ao investir 56,19\% dos recursos totais recebidos do FNDE na agricultura familiar, enquanto o município A aplicou 42,16\%. Esta diferenciação no uso dos recursos fica mais evidenciada, se for analisado o histórico dos dois municípios de 2010 a 2014, já que o município A teve uma média de aquisições de 20,04\% e o município B de 45,68\%.

Tabela 1. Recursos aplicados à alimentação escolar no ano de 2013 e número de alunos por nível de ensino nos municípios investigados.

\begin{tabular}{|c|c|c|c|c|}
\hline \multirow{2}{*}{\multicolumn{3}{|c|}{ Total de investimentos }} & Município A & Município B \\
\hline & & & $27.641,06$ & $169.076,73$ \\
\hline \multicolumn{3}{|c|}{ Valor recebido pelo FNDE } & $23.120,00$ & $109.400,00$ \\
\hline \multicolumn{3}{|c|}{ Percentual de contrapartida do município $(\%)$} & 19,55 & 54,55 \\
\hline \multicolumn{3}{|c|}{ Valor aplicado em Chamada Pública } & $9.747,50$ & $61.467,15$ \\
\hline \multicolumn{3}{|c|}{ Valor aplicado em Licitação } & $17.894,00$ & $107.609,58$ \\
\hline \multicolumn{3}{|c|}{ Percentual de investimento de recursos do FNDE à agricultura familiar (\%) } & 42,16 & 56,19 \\
\hline \multicolumn{3}{|c|}{ Percentual médio de investimentos na agricultura familiar de 2010 a $2014(\%)$} & 20,04 & 45,68 \\
\hline \multicolumn{3}{|l|}{ Total de Estudantes } & 287 & 1358 \\
\hline \multirow{4}{*}{ Ensino Fundamental } & \multirow{2}{*}{ Anos Iniciais } & Parcial & 184 & 1041 \\
\hline & & Integral & 62 & 0 \\
\hline & \multirow{2}{*}{ Anos Finais } & Parcial & 0 & 0 \\
\hline & & Integral & 0 & 0 \\
\hline \multirow{2}{*}{\multicolumn{2}{|c|}{ Médio }} & Parcial & 0 & 0 \\
\hline & & Integral & 0 & 0 \\
\hline \multicolumn{3}{|c|}{ Valor Per Capita Investido } & 0,47 & 0,61 \\
\hline
\end{tabular}

Fonte: Censo Escolar, 2013. Prestações de contas, 2013, FNDE (2015). Adaptado pelas autoras.

Nota: valores/investimentos expressos em Reais. 
Comparando-se o planejamento alimentar dos dois municípios, o município B, apresentou valores nutricionais mais adequados com refeições normocalóricas, normoglicídicas, normoproteicas e hipolipídicas (Tabela 2).

Tabela 2. Valores médios, percentual de adequação em relação ao recomendado e desvio-padrão, da oferta de nutrientes do cardápio planejado dos municípios A e B

\begin{tabular}{|c|c|c|c|c|c|c|c|c|}
\hline Nutrientes & Município & Referência & $\begin{array}{l}\text { Média na } \\
\text { Semana }\end{array}$ & $\begin{array}{c}\% \text { de } \\
\text { Adequação }\end{array}$ & DP & Mínimo & Máximo & $p$ \\
\hline \multirow{2}{*}{$\begin{array}{c}\text { Energia } \\
\text { (kcal) }\end{array}$} & $\mathrm{A}$ & \multirow{2}{*}{367,50} & 302,30 & 82,26 & 166,21 & 153,62 & 561,14 & \multirow{2}{*}{0,757} \\
\hline & $\mathrm{B}$ & & 370,10 & 100,71 & 150,76 & 188,66 & 577,45 & \\
\hline \multirow{2}{*}{$\begin{array}{c}\text { Carboidratos } \\
\text { (g) }\end{array}$} & A & \multirow{2}{*}{59,75} & 28,89 & 48,35 & 18,52 & 9,37 & 58,92 & \multirow{2}{*}{0,173} \\
\hline & B & & 66,75 & 111,72 & 35,73 & 29,01 & 117,51 & \\
\hline \multirow{2}{*}{$\begin{array}{l}\text { Proteínas } \\
\text { (g) }\end{array}$} & A & \multirow{2}{*}{11,50} & 12,20 & 106,10 & 6,94 & 7,19 & 24,32 & \multirow{2}{*}{0,751} \\
\hline & B & & 11,30 & 98,23 & 8,94 & 2,36 & 26,08 & \\
\hline \multirow{2}{*}{$\begin{array}{l}\text { Lipídios } \\
(\mathrm{g})\end{array}$} & A & \multirow{2}{*}{9,20} & 15,32 & 166,59 & 10,45 & 6,77 & 31,06 & \multirow{2}{*}{0,017} \\
\hline & B & & 6,43 & 69,93 & 3,43 & 1,90 & 11,50 & \\
\hline \multirow{2}{*}{$\begin{array}{l}\text { Fibras } \\
(\mathrm{g})\end{array}$} & A & \multirow{2}{*}{5,75} & 1,08 & 18,78 & 0,78 & 0,00 & 2,20 & \multirow{2}{*}{0,044} \\
\hline & B & & 2,94 & 51,13 & 2,12 & 1,00 & 5,90 & \\
\hline \multirow{2}{*}{$\begin{array}{c}\mathrm{A} \\
(\mu \mathrm{g})\end{array}$} & A & \multirow{2}{*}{120,00} & 94,40 & 78,67 & 132,46 & 0,00 & 294,00 & \multirow{2}{*}{0,192} \\
\hline & B & & 164,58 & 137,15 & 174,47 & 2,60 & 365,70 & \\
\hline \multirow{2}{*}{$\begin{array}{c}\mathrm{C} \\
(\mathrm{mg})\end{array}$} & A & \multirow{2}{*}{9,50} & 75,18 & 791,37 & 145,86 & 0,00 & 334,10 & \multirow{2}{*}{0,062} \\
\hline & $\mathrm{B}$ & & 14,28 & 150,32 & 22,98 & 0,00 & 53,60 & \\
\hline \multirow{2}{*}{$\begin{array}{c}\mathrm{Ca} \\
(\mathrm{mg})\end{array}$} & A & \multirow{2}{*}{235,00} & 75,18 & 30,63 & 89,29 & 0,00 & 334,10 & \multirow{2}{*}{0,968} \\
\hline & B & & 87,04 & 37,04 & 81,46 & 24,40 & 204,20 & \\
\hline \multirow{2}{*}{$\begin{array}{c}\mathrm{Fe} \\
(\mathrm{mg})\end{array}$} & A & \multirow{2}{*}{1,95} & 1,44 & 73,85 & 1,60 & 0,00 & 4,00 & \multirow{2}{*}{0,694} \\
\hline & B & & 1,80 & 92,31 & 1,42 & 0,20 & 4,10 & \\
\hline \multirow{2}{*}{$\begin{array}{l}\mathrm{Mg} \\
(\mathrm{mg})\end{array}$} & A & \multirow{2}{*}{50,00} & 14,04 & 28,08 & 14,61 & 0,00 & 37,30 & \multirow{2}{*}{0,264} \\
\hline & $\mathrm{B}$ & & 28,86 & 57,72 & 25,41 & 5,00 & 67,40 & \\
\hline \multirow{2}{*}{$\begin{array}{c}\mathrm{Zn} \\
(\mathrm{mg})\end{array}$} & A & 155 & 0,88 & 56,77 & 0,86 & 0,00 & 2,10 & 0. \\
\hline & B & 1,50 & 0,88 & 56,77 & 1,06 & 0,00 & 2,70 & 0,804 \\
\hline Gordura & A & $408 *$ & 2,62 & 64,16 & 1,97 & 0,00 & 5,20 & 0758 \\
\hline Saturada & B & $4,00^{2}$ & 1,64 & 40,16 & 1,63 & 0,00 & 3,70 & 0,130 \\
\hline Sódio & A & $40000 * *$ & 792,60 & 198,15 & 655,44 & 0,10 & 1433,30 & 0157 \\
\hline & B & & 462,96 & 115,74 & 465,76 & 1,30 & 1163,40 & \\
\hline
\end{tabular}

* $10 \%$ da energia total proveniente de gordura saturada.

** $400 \mathrm{mg}$ (quatrocentos miligramas) de sódio per capita, em período parcial, quando ofertada uma refeição. 
Ambos os cardápios apresentaram ampla dispersão dos valores de energia nos distintos dias da semana, com valores distantes da média, sendo que o município $\mathrm{B}$ apresentou valor médio próximo ao limite inferior de tolerância. Tratandose dos macronutrientes, os dois municípios alcançaram o recomendado para proteínas. No entanto, só o município B apresentou adequação para carboidratos. Os valores de lipídeos foram significativamente diferentes $(\phi<0,05)$, já que o cardápio do município A demonstrou-se hiperlipídico e o do B hipolipídico (Tabela 2).

Considerando os valores energéticos próximos ao limite inferior recomendado do município A, salienta-se que a baixa ingestão de energia pode propiciar o fornecimento insuficiente de importantes nutrientes relacionados ao metabolismo energético, à reparação tecidual, ao sistema antioxidante e à resposta imunológica dos escolares ${ }^{[17]}$. É fundamental a ingestão de alimentos em quantidades suficientes a fim de que não sejam ultrapassadas ou inalcançadas as necessidades nutricionais dos indivíduos, para que sejam prevenidas patologias relacionadas à falta e excesso de alimentos $^{[17]}$.

Em relação ao quantitativo de fibras, ambos os planejamentos avaliados não permitiram $\mathrm{o}$ alcance de sua recomendação. Todavia, foram encontradas diferenças significativas $(p<0,05)$ nas quantidades ofertadas em cada um dos municípios. No planejamento do município B, os valores encontrados chegaram mais próximos à adequação (Tabela 2).

O planejamento de refeições hiperlipídicas e reduzido em fibras pelo município A se soma com a elevada quantidade de sódio (Tabela 2) encontrada (já que a Resolução 26/2013 $3^{[10]}$ recomenda claramente o valor máximo permitido de $400 \mathrm{mg} /$ dia deste último micronutriente) ${ }^{[15]}$. Ressalta-se assim para o risco de alterações metabólicas nos escolares, que, ligados às práticas alimentares errôneas já evidenciadas nesta faixa etária, agravariam tal problema ${ }^{[18]}$.
No que tange aos outros micronutrientes, verificou-se o alcance das recomendações para alguns, em ambos os cardápios, mas principalmente no município $B$. O cardápio planejado apresentou valores adequados ou superiores para vitamina C e vitamina A e adequados de ferro (Tabela 2 ).

Em especial, salienta-se que os resultados encontrados para vitamina $\mathrm{C}$ neste estudo foram similares a outro trabalho no qual $75 \%$ dos cardápios que foram analisados também alcançaram as recomendações de vitamina C, sendo que a oferta média encontrada também foi superior ao valor de referência ${ }^{[13]}$. Ademais, os quantitativos inferiores em relação à recomendação para zinco e principalmente cálcio, encontrados pelo mesmo estudo ${ }^{[13]}$, também foram similares aos resultados aqui encontrados.

Tais achados também são semelhantes a outro trabalho no qual foi verificada uma oferta insuficiente de cálcio em ambas as faixas etárias no cardápio escolar avaliado, e no qual também foram identificados valores superiores ao recomendado para vitamina A, C e ferro ${ }^{[19]}$.

A dificuldade em se alcançar as recomendações de cálcio em regiões com uma rica produção de laticínios, como as dos municípios investigados, demonstra-se um contrassenso, já que a compra de leite e derivados não foi realizada pela chamada pública (com exceção de queijo colonial). No município A, por exemplo, onde os valores planejados para cálcio foram menores, a produção local chega a ser superior à do município $\mathrm{B}^{[20,21]}$. Nesse sentido, este achado leva a questionar os motivos pelos quais os gestores não adquiriram ou adquirem em quantidades adequadas estes produtos de agricultores familiares.

Dentre outros aspectos, isto pode ser explicado pela limitação que os agricultores familiares encontram para atender às exigências sanitárias e formalidades exigidas para sua comprovação, no que se refere aos produtos de 
origem animal ${ }^{[8,22]}$, tornando a venda inviável ou impossível para as realidades locais, o quê faz deste um importante aspecto a ser trabalhado no âmbito da agricultura familiar. Tal afirmação pode ser corroborada por outro estudo ${ }^{[23]}$ que analisou chamadas públicas e prestações de contas da alimentação escolar praticadas em municípios do Paraná. Seus resultados demonstraram que a quantidade de produtos de origem animal adquiridos pelos municípios foi consideravelmente inferior aos de origem animal, tais como o leite e derivados, carnes, ovos e peixes.

Além disso, outro trabalho realizado no Paraná, ao verificar ausência de compra de produtos de origem animal de agricultores familiares, aponta para a falta de uma legislação sanitária brasileira condizente com as agroindústrias familiares, comunitárias e artesanais. Isso por que, segundo os autores do trabalho, os mercados institucionais como a alimentação escolar demandam a regularização das agroindústrias familiares, cujas características não se enquadram em muitas exigências da legislação sanitária existente ${ }^{[24]}$.

Com relação à análise da composição das compras, ambos os municípios apresentaram maior aplicação dos recursos totais em alimentos recomendados (Figura 1).

A modalidade de licitação pregão presencial teve maior percentual de investimentos para compra de produtos controlados (processados e industrializados) nos dois municípios (Figura 2), enquanto que as chamadas públicas, destinadas à compra de produtos da agricultura familiar, continham produtos recomendados em maior proporção.

Figura 1. Distribuição total de alimentos em recomendados e controlados dos municípios A e B

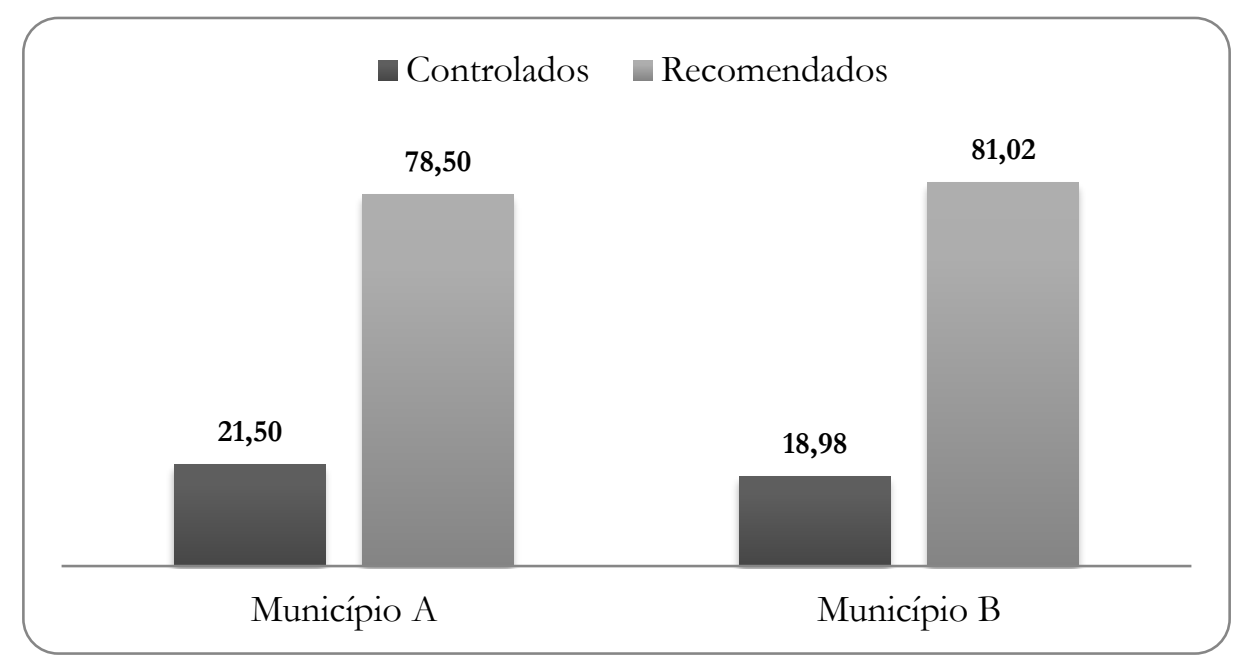


Figura 2. Distribuição percentual de alimentos recomendados e controlados dos municípios A e B, em relação ao total de compras, por via de compras

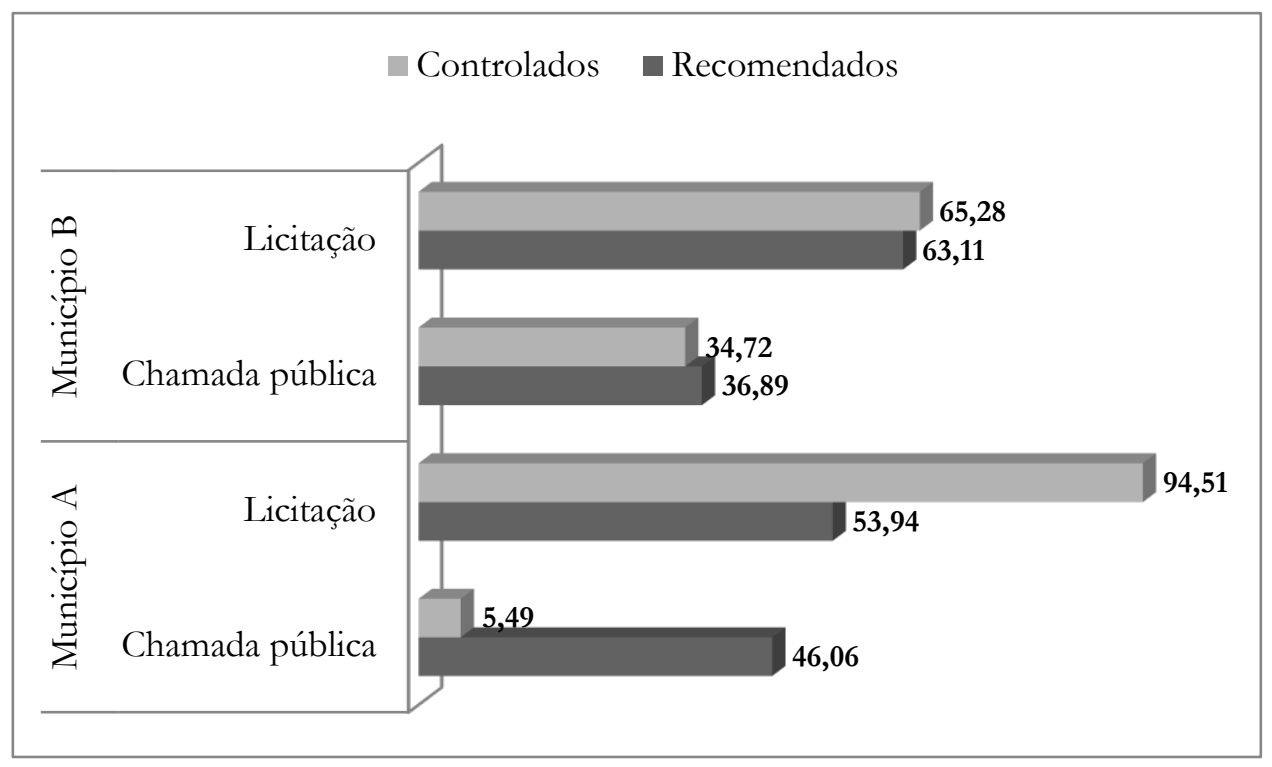

Quanto a isso, autores recomendam a exclusão de alimentos com elevado processamento dos cardápios para a alimentação escolar, sendo preferível a presença de alimentos básicos e saudáveis, pertencentes à cultura alimentar local ${ }^{[25]}$.

Analisando as duas modalidades de compras, verificou-se que em ambos os municípios não houve nenhuma compra de oleaginosas. O município A planejou a aquisição superior de alimentos processados e ultraprocessados (A: 5,24\%; B: 0,57\%), além de realizar menor investimento em alimentos integrais (A:0,00\%; B:0,76\%). O município B por sua vez, realizou investimentos percentuais superiores para a aquisição de carnes gordurosas, embutidos ou produtos cárneos industrializados, queijos e molhos com alto teor de sódio e/ou gordura saturada (coxa de frango, salame, apresuntado e salsicha) (A: 3,60\%; B: 5,37\%), além de alimentos com alto teor de açúcar e açucarados (bolachas, melado, açúcar mascavo e doce de frutas, chocolate em pó, pó para pudim, iogurte, entre outros) (A: 10,5\%; B: 12,58\%).
No que se refere aos alimentos controlados adquiridos pelo município $\mathrm{B}$, a aquisição de açúcares e alguns doces é justificada pelo fato de que este município apresenta importante produção local de cana de açúcar e seus subprodutos. Assim, torna-se desapropriado ajuizar como inadequada tal aquisição, já que este tipo de açúcar se caracteriza por menor grau de processamento e aspectos nutricionais positivos em comparação ao refinado. Salienta-se também que na análise quantitativa do cardápio o município apresentou valores adequados de energia e carboidratos, o que, portanto, indica o uso moderado deste produto.

Em relação a isso, outro estudo também observou que a agricultura familiar foi a principal via de oferta de alimentos regionais, como é o caso do açúcar de cana e doces adquiridos no município $\mathrm{B}^{[26]}$.

No que tange às chamadas públicas, $\mathrm{O}$ município $\mathrm{B}$, destacou-se positivamente pela aquisição superior de frutas $(37,89 \%)$, verduras e legumes $(17,62 \%)$, enquanto que o município $A$, investiu percentuais importantes no grupo de 
cereais, pães, massas, farinhas e fermentos $(34,19 \%)$.

O maior investimento em frutas legumes e verduras (município B: 55,51\%), bem como, cereais tubérculos e raízes (município A: 34,19\%) encontrado no estudo em questão, se contrapõe ao referido por outro trabalho desenvolvido com nove municípios do Sudoeste do Paraná. Nos seus resultados foi demonstrado que apenas $27,6 \%$ de investimentos eram destinados à frutas, verduras e legumes e $0,60 \%$ em cereais, tubérculos e raízes ${ }^{[27]}$.

Houve maior variedade (número de itens) de produtos nas compras do município $\mathrm{B}$ (Chamada Pública: 34; Pregão Presencial: 81; Total: 115) em relação ao A (Chamada Pública: 12; Pregão Presencial: 47; Total:59). Mesmo assim, a análise das chamadas públicas nos dois municípios também demonstrou reduzida variedade de produtos de origem animal, como carnes e leites e derivados em especial.

Quanto à variedade de produtos adquiridos pelas compras, mais especialmente pelas chamadas públicas, os resultados obtidos pelo município B (34 produtos) foram similares aos encontrados por outro estudo, o qual encontrou a aquisição de 35 produtos alimentares provenientes da agricultura familiar ${ }^{[24]}$. Mesmo assim, tanto estes resultados quanto o encontrado no município A, de maneira mais específica, justificam a afirmação de outros autores ${ }^{[28]}$ de que apesar de os municípios adquirirem produtos da agricultura familiar como recomendando pela Lei 11.947/2009, a variedade dos mesmos necessita ainda ser expandida, a fim de contribuir para a formação de hábitos alimentares saudáveis dos escolares.

Ainda nesse contexto, é notório salientar que nenhum dos municípios realizou a compra de produtos orgânicos ou agroecológicos de agricultores familiares. Isso reflete para uma realidade observada também em outros trabalhos publicados no Brasil, nos quais foi verificada reduzida ou nenhuma compra destes produtos para a alimentação escolar ${ }^{[22,24,27,29]}$. Tal aspecto é explicado pelo desconhecimento dos diversos atores no que tangen aos benefícios destes alimentos (gestores, agricultores e técnicos), pela reafirmação da produção convencional e pelos reduzidos incentivos a esta produção ${ }^{[27]}$.

Por fim, os resultados apresentados exprimem que a efetividade do PNAE depende principalmente da eficácia e da eficiência na adequada utilização dos recursos. Neste estudo, a compra superior de produtos da agricultura familiar, associado ao acréscimo de contrapartida e o valor per capita planejado pelo município B, influenciou positivamente na elaboração de cardápios escolares mais adequados.

Assim, os resultados encontrados se contrapõem aos apresentados por outro estudo com objetivos semelhantes ${ }^{[9]}$, no qual a aquisição de produtos da agricultura familiar não foi suficiente para promover cardápios mais adequados, e o qual demonstrou que o município que adquiria produtos da agricultura familiar apresentou menor adequação de macro e micronutrientes em comparação ao cardápio do município que não o fazia.

Ademais partir do que foi observado no estudo em questão e pautando-se nos apontamentos já trazidos por outros autores ${ }^{[7-9]}$, infere-se que a qualidade da alimentação escolar poderia ser potencializada por uma compra superior a $30 \%$ dos recursos disponibilizados pelo FNDE, visto que a contrapartida também poderia aprimorar a qualidade das refeições quando utilizada para estes fornecedores. Nessa linha de pensamento, são relevantes os incentivos (legislações municipais ou federais), para que a contrapartida também passe a ser contabilizada no valor mínimo exigido de aplicação de $30 \%$ de investimentos a estes fornecedores. 
As análises aqui desenvolvidas justificamse por questionar, no âmbito da alimentação escolar, tanto a qualidade nutricional, quanto a aplicação dos recursos públicos em meio ao processo de compras local. Reforça-se a importância de considerar como os recursos são utilizados, se estes estão sendo investidos conforme a legislação e de acordo com os hábitos alimentares, a cultura e tradição alimentar da localidade, pautando-se na sustentabilidade e diversificação agrícola da região ${ }^{[30]}$.

\section{CONCLUSÃO}

Os resultados apresentados indicam que no município com maior aquisição de alimentos da agricultura familiar houve o planejamento de cardápio mais adequado do ponto de vista nutricional. Porém, nutrientes importantes para a faixa etária avaliada encontraram-se em quantidades inferiores às recomendadas em ambos os municípios (cálcio, zinco e magnésio). Assim, é importante dar maior atenção ao planejamento dos cardápios e compras, considerando os alimentos ainda não adquiridos fontes destes nutrientes que potencialmente podem vir da agricultura familiar da região, como laticínios e peixes, oleaginosas sementes e grãos integrais.

Os resultados também demonstraram investimentos ainda reduzidos para a aquisição de itens da agricultura familiar, quando considerada a variedade de itens alimentares, mas especialmente no que se refere a produtos orgânicos e agroecológicos. Nesta lógica, enfatiza-se que a aquisição de alimentos de agricultores familiares pautada na aproximação da produção e consumo, com a garantia de produtos mais frescos, maior concentração de compostos bioativos e de refeições escolares mais diversificadas se apresenta como uma potencial estratégia para se contrapor à perspectiva mundial de ocidentalização da cultura alimentar e unificação dos gostos a partir da abreviação da variedade alimentar.
Para além do aspecto nutricional, reforçam-se os vários aspectos positivos relacionados a esta compra, tanto para escolares quanto para os próprios agricultores familiares, como a manutenção da cultura alimentar e de estilos de produção, manutenção de agricultores no campo, garantia de renda, desenvolvimento local, preservação da biodiversidade, meios sustentáveis de produção, ambos factíveis para a segurança alimentar e nutricional.

Em contrapartida é importante ressaltar as limitações do estudo no que tange à metodologia utilizada. $\mathrm{Na}$ análise quantitativa dos cardápios não foram considerados restos e sobras dos alimentos, possíveis ajustes nas preparações, estimativa dos valores per capitas reais dos alimentos, consumo de alimentos por parte de professores e colaboradores e adesão dos escolares às refeições.

No entanto, os métodos aqui utilizados, quando combinados, apresentaram-se de valia para a avaliação dos cardápios e compras realizados pelo profissional nutricionista e gestores em meio às suas atribuições no âmbito da alimentação escolar, com potencial para serem utilizados em amostras maiores a fim de um diagnóstico mais amplo dessa realidade no Brasil.

Por fim, aponta-se para a necessidade de se avaliar outros aspectos intrínsecos à qualidade, não mensurados neste estudo, uma vez que a qualidade alimentar e as nuances em torno da alimentação e da segurança alimentar e nutricional vão além da questão nutricional e organoléptica, ampliando-se também para questões sociais, culturais, ambientais, e ressignificações relacionadas à construção social que são expostas a permanente mudança.

\section{REFERÊNCIAS}

[1] Food and Agriculture Organization of the United Nations (FAO). Alimentación escolar y las posibilidades de compra directa de la agricultura familiar. Estudio de caso en ocho países. Fortalecimiento de Programas de Alimentación 
Escolar en el Marco de la Iniciativa América Latina y Caribe Sin Hambre 2025. Roma; 2013.

[2] Fundo Nacional de Desenvolvimento da Educação FNDE. Histórico do Programa Nacional de Alimentação Escolar [internet]. Brasillia; 2014 [acesso em 14 jan 2017]. Disponível em: http://www.fnde.gov.br

[3] Brasil. Lei no 11.947, de 16 de junho de 2009. Dispõe sobre o atendimento da alimentação escolar e do Programa Dinheiro Direto na Escola aos alunos da educação básica; altera as Leis nos 10.880, de 9 de junho de 2004, 11.273, de 6 de fevereiro de 2006, 11.507, de 20 de julho de 2007; revoga dispositivos da Medida Provisória no 2.178-36, de 24 de agosto de 2001, e a Lei no 8.913, de 12 de julho de 1994; e dá outras providências. Diário Oficial da União. 16 jun 2009.

[4] Triches RM, Schneider S. Desestruturar para construir: interfaces para a agricultura familiar acessar o programa de alimentação escolar. Estud Soc e Agric. 2012;20(1):66-105.

[5] Souza LBB. Organizações da agricultura familiar no estado de São Paulo e sua experiência de fornecimento para o PNAE. In: Corá MAJ \& Belik W. Análise da inclusão da agricultura familiar na alimentação escolar no estado de São Paulo. Ministério do desenvolvimento agrário. Projeto Nutre SP. -- São Paulo: Instituto Via Pública; 2012.

[6] Melão IB. Produtos sustentáveis na alimentação escolar: o PNAE no Paraná. Cad. IPARDES. 2012 [acesso em 12 dez 2016]; 2(2): 87-105. Disponível em: http://www.organicsnet.com.br/wpcontent/uploads/Artigo-Final-533-2301-1-PB.pdf.

[7] Guzzati TC, Sampaio CAC, Turnes VA. Novas relações entre agricultores familiares e consumidores: perspectivas recentes no Brasil e na França. Organizações Rurais \& Agroindustriais. 2014;16(3):363-375.

[8] Triches RM, Schneider S. Alimentação Escolar e Agricultura Familiar: reconectando o consumo à produção. Saúde Soc. 2010;19(4):933-45.

[9] Belik W, Domene SMÁ. Experiências de programas combinados de alimentación escolar y desarrollo local en São Paulo, Brasil. Agroalimentaria [internet]. 2012 [acesso em 2016 out 20];18(34):57-72. Disponível em: http://www.saber.ula.ve/bitstream/123456789/35379/1/a rt4.pdf

[10] Brasil. Resolução no 26 de 17 de junho de 2013. Dispõe sobre o atendimento da alimentação escolar aos alunos da educação básica no âmbito do Programa Nacional de
Alimentação Escolar - PNAE. Diário Oficial da União. 26 jun 2013.

[11] Nunes RM. Tabelas de Per Capita e Fatores de Correção e Rendimento [internet]. Rio de Janeiro; 2014 [acesso em 22 nov 2017]. Disponível em: http:/ /www.ufjf.br

[12] Anjos MCR. Relação de fatores de correção e índice de conversão (cocção) de alimentos [internet]. Curitiba; 2014 [acesso em 14 jan 2017]. Disponível em: http://people.ufpr.br/ monica.anjos/Fatores.pdf.

[13] Domene SMA, Chaim NA, Turpin ME, Menezes F. A alimentação na Escola: uma avaliação qualitativa. In: Sawaya AL et al., organizador. Desnutrição, pobreza e sofrimento psíquico. São Paulo: Editora da Universidade de São Paulo; 2011.

[14] Avanutri. Avanutri - Equipamentos para avaliação nutricional. Três Rios: Avanutri; 2016.

[15] IBM SPSS - Statistical Package for the Social Science. Statistics for Windows Version 19.0. Armonk: Business Analytics; 2010.

[16] Martinelli SS, Soares P, Fabri RK, Veiros MB, Cavalli SB. Qualidade da alimentação escolar: método para avaliação da aquisição de gêneros alimentícios (AGA). In: Teo CRPA, Triches RM. Alimentação Escolar: construindo interfaces entre saúde, educação e desenvolvimento. Chapecó: Argos; 2016. p. 345-378.

[17] American Dietetic Association, Dietitians of Canada, American College of Sports Medicine. Position of American Dietitic Association, Dietitians of Canada, and American College of Sports Medicine: nutritrion and athletic performance. J Am Diet Assoc. 2001;100(12):1543-56.

[18] Veiga GV, Costa RS, Araújo MC, Souza AM, Bezerra IN, Barboza FS, et al. Inadequação do consumo de nutrientes entre adolescentes brasileiros. Rev Saúde Pública. 2013;47(1 Supl):212S-21S.

[19] Silva MMDC, Gregório EL. Avaliação da composição nutricional dos cardápios da alimentação escolar das escolas da rede municipal de Taquaraçu de Minas - MG. HU Revista. 2012;37(3):387-394.

[20] Instituto Paranaense de Desenvolvimento Econômico e Social - IPARDES. Caderno estatístico do município de Sulina [internet]. Curitiba; 2015 [acesso em 14 jan 2017]. Disponível em: http://www.ipardes.gov.br 
[21] Instituto Paranaense de Desenvolvimento Econômico e Social - IPARDES. Caderno estatístico do município de Capitão Leônidas Marques [internet]. Curitiba; 2015 [acesso em 14 jan 2017]. Disponível em: http://www.ipardes.gov.br/cadernos/MontaCadPdf1.php? Municipio $=85790$.

[22] Gonçalves HVB, Cunha DS, Stedefeldt E, Rosso VV. Family farming products on menus in school feeding: a partnership for promoting healthy eating. Ciência Rural. 2015 [acesso em 2016 nov 22];45(12):2267-2273. Disponível em: http://www.scielo.br/scielo.php?script=sci_arttext\&pid=S0 103>.http://dx.doi.org/10.1590/0103$8478 \mathrm{cr} 201502148478201500120226$. doi:http://dx.doi.org/10.1590/0103-8478cr20150214.

[23] Triches RM, Barbosa LP, Silvestri F. Agricultura Familiar e Alimentação Escolar no Estado do Paraná: uma análise das chamadas públicas. Rev Paran Desenv. 2016;37(130):29-43.

[24] Santana SO. Caracterização do consumo alimentar e seus determinantes entre adolescentes de escolas públicas e privadas das capitais brasileiras e do Distrito Federal. [dissertação]. Brasilia (DF): Universidade de Brasilia; 2014.

[25] Teo CRPA, Monteiro CA. Marco legal do Programa Nacional de Alimentação Escolar: uma releitura para alinhar propósitos e práticas na aquisição de alimentos. Rev Nutr. 2014;25(5):657-668.

[26] Fabri RK. Uso de alimentos regionais da agricultura familiar na alimentação escolar: um estudo de caso em Santa Catarina [dissertação]. Florianópolis: Universidade Federal de Santa Catarina; 2013.

[27] Triches RM, Schabarum JC, Giombelli GP. Demanda de produtos da agricultura familiar e condicionantes para a aquisição de produtos orgânicos e agroecológicos pela alimentação escolar no sudoeste do estado do Paraná. Rev NERA. 2016 [acesso em 2017 jan 14];19(31):91-110. Disponível em: http://revista.fct.unesp.br

[28] Toyoyoshi JY, Oliveira R, Santos MSN, Galisa MS, Galante AP. Avaliação da aquisição de gêneros alimentícios provenientes da agricultura familiar para a alimentação escolar. O Mundo da Saúde. 2013;37(3):329-335.

[29] Santos F., Fernandes PS, Rockett FC, Oliveira ABA. Avaliação da inserção de alimentos orgânicos provenientes da agricultura familiar na alimentação escolar, em municípios dos territórios rurais do Rio Grande do Sul, Brasil. Ciência \& Saúde Coletiva. 2014;19(5):1429-1436.
[30] Villar BS, Schwartzman F, Januario BL, Ramos JF. Situação dos municípios do estado de São Paulo com relação à compra direta de produtos da agricultura familiar para $\mathrm{O}$ Programa Nacional de Alimentação Escolar (PNAE). Rev Bras Epidemiol. 2013;16(1):223-6. 